\title{
Antiviral Efficacy of Pralatrexate against SARS-CoV-2
}

\author{
Joon-Yong Bae ${ }^{1, \dagger}$, Gee Eun Lee ${ }^{1, \dagger}$, Heedo Park ${ }^{1}$, Juyoung Cho', Jeonghun Kim¹, Jungmin Lee ${ }^{1}$, Kisoon Kim ${ }^{1}$, \\ Jin II Kim ${ }^{1,2, *}$ and Man-Seong Park ${ }^{1,2, *}$ \\ ${ }^{1}$ Department of Microbiology, Institute for Viral Diseases, Korea University College of Medicine, Seoul 02841, \\ ${ }^{2}$ Biosafety Center, Korea University College of Medicine, Seoul 02841, Republic of Korea
}

\begin{abstract}
Novel coronavirus (SARS-CoV-2) has caused more than 100 million confirmed cases of human infectious disease (COVID-19) since December 2019 to paralyze our global community. However, only limited access has been allowed to COVID-19 vaccines and antiviral treatment options. Here, we report the efficacy of the anticancer drug pralatrexate against SARS-CoV-2. In Vero and human lung epithelial Calu-3 cells, pralatrexate reduced viral RNA copies of SARS-CoV-2 without detectable cytotoxicity, and viral replication was successfully inhibited in a dose-dependent manner. In a time-to-addition assay, pralatrexate treatment at almost half a day after infection also exhibited inhibitory effects on the replication of SARS-CoV-2 in Calu-3 cells. Taken together, these results suggest the potential of pralatrexate as a drug repurposing COVID-19 remedy.
\end{abstract}

Key Words: Antiviral, COVID-19, Drug repurposing, SARS-CoV-2

\section{INTRODUCTION}

Severe acute respiratory syndrome coronavirus 2 (SARSCoV-2) causes an unprecedented pandemic disease (COVID-19) (The Lancet, 2020). Since its first case was reported in China, in December 2019, the virus has resulted in more than 100 million human infections in more than 200 countries, territories, and areas with an almost $2.16 \%$ case-fatality rate (based on the data of World Health Organization COVID-19 Dashboard, as of January 21, 2021) (WHO, 2020a). Needless to say, COVID-19 has been socially and economically paralyzing our global community (Van Lancker and Parolin, 2020; Jones et al., 2021). To address this global disaster, many potential COVID-19 vaccine candidates have been investigated (WHO, 2021b). Of them, mRNA-based Pfizer-BioNTech and Moderna vaccines have been recommended for use, and three other candidates are being or will be under Phase 3 clinical trials in the United States (CDC, 2021c). As of January 31,2021 , almost 50 million doses of COVID-19 vaccines have been distributed in the U.S., and more than 25 million people were administered at least one dose (CDC, 2021a). However, approximately one million new cases have been reported in the U.S. during the last week of January 2021 (CDC, 2021b), and the situation is almost the same in Europe (ECDC, 2021). Hence, it is urgently needed to prepare another medical intervention method, such as therapeutic drugs, to fight against contagion.

Drug repositioning uses an approved drug beyond its original targeted purpose. At the time of the pandemic caused by an unprecedented novel virus, it may be a time-saving strategy compared to developing a completely new drug. In this regard, several approved drugs have been investigated for their potential effects on COVID-19 (WHO, 2020b). Given the interim results of the WHO Solidarity Trial (Consortium et al., 2020), remdesivir, hydroxychloroquine, lopinavir, and interferon regimens appeared to have unsatisfiable effects on COVID-19 patients. Of these drugs, remdesivir was the only drug authorized by the U.S. Food and Drug Administration (FDA) for the emergency treatment of COVID-19 patients, whereas the use of chloroquine (or hydroxychloroquine) with or without azithromycin, lopinavir/ritonavir, and ivermectin was not recommended (FDA, 2020). Consistently, Beigel et al. (2020) reported the beneficial effects of remdesivir on the recovery time in COVID-19 patients. To fight against COVID-19, however, the Solidarity Trial is still seeking other treatment methods, including corticosteroids (WHO, 2021a). In search of a

\section{Open Access https://doi.org/10.4062/biomolther.2021.032}

This is an Open Access article distributed under the terms of the Creative Commons Attribution Non-Commercial License (http://creativecommons.org/licenses/by-nc/4.0/) which permits unrestricted non-commercial use, distribution, and reproduction in any medium, provided the original work is properly cited.
Received Feb 8, 2021 Revised Feb 26, 2021 Accepted Mar 1, 2021 Published Online Mar 17, 2021

\section{*Corresponding Authors}

E-mail: manseong.park@gmail.com (Park MS),jinil_kim@korea.ac.kr (Kim J) Tel: +82-2-2286-1312 (Park MS), +82-2-2286-1313 (Kim Jl) Fax: +82-2-923-3645 (Park MS), +82-2-923-3645 (Kim Jl)

${ }^{\dagger}$ The first two authors contributed equally to this work. 
candidate drug that can be successfully listed in the treatment options for COVID-19 patients, we also examined several candidate drugs and reported the anti-SARS-CoV-2 efficacy of the anticancer drug pralatrexate, which has been used to treat relapsed or refractory peripheral T-cell lymphoma (Hong et al., 2019).

\section{MATERIALS AND METHODS}

\section{Cells and viruses}

Vero, Calu-3, and Madin-Darby canine kidney (MDCK) cells were purchased from the Korean Cell Line Bank (Seoul, Korea). The cells were maintained in Dulbecco's modified Eagle's medium (DMEM; Gibco, Thermo Fisher Scientific, Waltham, MA, USA) supplemented with $10 \%$ fetal bovine serum (FBS; Serana, Pessin, Germany) and penicillin-streptomycin (Gibco). SARS-CoV-2 (BetaCoV/korea/KCDC03/2020, NCCP no. 43326) and A/Korea/01/2009 (2009 pandemic influenza strain, H1N1 subtype), which were provided by the Korea Disease Control and Prevention Agency (KDCA; Osong, Korea), were prepared by propagation in Vero cells and embryonated chicken eggs, respectively, after plaque purification. Other seasonal influenza viruses, such as A/Perth/16/2009 (H3N2 subtype), B/Brisbane/60/2008 (Victoria lineage), and B/Wisconsin/01/2010 (Yamagata lineage), were provided by II Yang Pharmaceutical Co. (Seoul, Korea) and prepared by propagation in embryonated chicken eggs after plaque purification. All the viruses were confirmed by commercial sequencing before use.

\section{Chemicals}

Pralatrexate was purchased from Selleckchem Chemicals LIc (Houston, TX, USA). Hydroxychloroquine sulfate was purchased from Sigma-Aldrich (St. Louis, MO, USA). These chemicals were dissolved in dimethyl sulfoxide (DMSO; Sigma-Aldrich) or deionized water to achieve a final concentration of $10 \mathrm{mM}$.

\section{Plaque assay}

A plaque assay was performed to determine infectious viral titers of SARS-CoV-2. Briefly, a confluent monolayer of Vero cells was prepared in advance and inoculated with diluted viruses. After $1 \mathrm{~h}$ of infection, the inoculum was discarded, and the cells were overlaid with DMEM-F12 (Sigma-Aldrich) containing $2 \%$ agarose. After $72 \mathrm{~h}$ at $37^{\circ} \mathrm{C}$ and $5 \% \mathrm{CO}_{2}$, the cells were stained with crystal violet (Georgia Chemicals Inc., Norcross, GA, USA).

\section{Plaque-reduction assay}

A confluent monolayer of MDCK cells was prepared in advance, and the cells were inoculated with $10^{2}$ plaque-forming units (pfu) of influenza viruses. After $1 \mathrm{~h}$ of infection, the inoculum was discarded, and the cells were overlaid with DMEMF12 (Sigma-Aldrich) containing 2\% agarose and serially twofold diluted pralatrexate. After $72 \mathrm{~h}$ at $37^{\circ} \mathrm{C}$ and $5 \% \mathrm{CO}_{2}$, the cells were stained with crystal violet (Georgia Chemicals Inc.). Control wells were treated with phosphate-buffered saline (PBS).

\section{Cell viability assay}

The cytotoxicity of the chemicals was determined using the cell proliferation reagent WST-1 (Roche, Basel, Switzerland) according to the manufacturer's instructions. Briefly, cells were seeded at a density of $2 \times 10^{4}$ cells/well (Vero) or $7 \times 10^{5}$ cells/well (Calu-3) in a 96-well clear flat-bottom TC-treated culture microplate (Thermo Fisher Scientific) and incubated with DMEM (Gibco) at $37^{\circ} \mathrm{C}$ and $5 \% \mathrm{CO}_{2}$. The next day, $2 \%$ FBS cell culture media were discarded and washed once with PBS. Then, serial twofold dilutions of the chemicals were added to each well. DMSO (Sigma-Aldrich) was used as a control. At 24 and $48 \mathrm{~h}$ postinfection (hpi), $10 \mu \mathrm{L} \mathrm{WST-1}$ was added to each well, followed by $2 \mathrm{~h}$ of incubation at $37^{\circ} \mathrm{C}$ and $5 \% \mathrm{CO}_{2}$. Subsequently, cell viability was determined using a microplate reader. The $50 \%$ cytotoxic concentration $\left(\mathrm{CC}_{50}\right)$ was calculated using GraphPad Prism 9 (GraphPad, San Diego, CA, USA).

\section{Real-time quantitative reverse transcription-polymerase chain reaction (qRT-PCR)}

Twelve-well plates (SPL Life Sciences, Pocheon, Korea) were seeded with $0.9 \times 10^{6}$ cells/well (Vero) or $1 \times 10^{6}$ cells/well (Calu-3) in advance. After $24 \mathrm{~h}$, the cells were washed once with PBS and infected with SARS-CoV-2 at a multiplicity of infection (MOI) of 0.01 or 0.1 for Vero or Calu- 3 cells, respectively. After $1 \mathrm{~h}$ of incubation at $37^{\circ} \mathrm{C}$ and $5 \% \mathrm{CO}_{2}$, the inoculum was discarded, and the cells were washed once with PBS. Subsequently, the cells were treated with serial twofold dilutions of the chemicals. At 24 and 48 hpi, viral RNAs extracted from the cell supernatants were quantified by qRT-PCR. Briefly, $130 \mu \mathrm{L}$ cell supernatants were harvested for RNA extraction with a Maxwell RSV Viral Total Nucleic Acid Purification kit (Promega, Madison, WI, USA). A SARS-CoV-2 RdRp region was amplified using forward (5'-GTGARATGGTCATGTGTGGCGG) and reverse (5'-CARATGTTAAASACACTATTAGCATA) primers and a probe (5'-FAMCAGGTGGAACCTCATCAGGAGATGC - BHQI) (Corman et al., 2020). The 50\% inhibitory concentration $\left(\mathrm{IC}_{50}\right)$ was calculated using GraphPad Prism 9 (GraphPad). A standard curve was generated based on the cycle-threshold values $\left(C_{T}\right.$ values $)$ corresponding to the known viral titers $\left(10^{0}-10^{6} \mathrm{pfu}\right)$ of SARS-CoV-2 in quantitative real-time RT-PCR targeted for the RdRp region.

\section{Growth kinetics}

The replication kinetics of SARS-CoV-2 were analyzed in Vero and Calu-3 cells. Briefly, monolayered Vero or Calu-3 cells in 12-well plates were inoculated with 0.01 or $0.1 \mathrm{MOI}$, respectively, for $1 \mathrm{~h}$. Then, the inoculum was discarded, and the cells were washed with DMEM (Gibco) three times and maintained with DMEM containing $2 \%$ FBS (Serana). Various concentrations of chemicals were added to the cell supernatants, and the cell supernatants were harvested at 24,48 , and $72 \mathrm{hpi}$ for titration by the plaque assay in Vero cells.

\section{Time-to-addition assay}

Confluent Calu-3 cell monolayers in 12-well tissue culture plates were inoculated with $0.1 \mathrm{MOI}\left(10^{5} \mathrm{pfu} / 100 \mu \mathrm{L}\right)$ of SARSCoV-2 for $1 \mathrm{~h}$. After infection, the inoculum was discarded, and the cells were washed with PBS once. DMEM (Gibco) containing $2 \%$ FBS (Serana) was added (nontreated group). Pralatrexate $(12.5 \mu \mathrm{M})$ was added to the medium at $1,3,5,7,9,11$, 13,25 , and $37 \mathrm{hpi}$. The cell supernatants were harvested at $48 \mathrm{~h}$ later from each drug addition time, and virus titers were determined by the plaque assay in Vero cells. 


\section{Statistical analysis}

The statistical significance of viral titer differences in the replication kinetics between the control (or virus-only) and drug-treated groups, two-way analysis of variance (ANOVA) with Dunnett's multiple comparisons test was applied using GraphPad Prism 9 (GraphPad). The results of the time-to-addition assay between the virus-only and drug-treated groups were analyzed by Student's $t$ test. ${ }^{*} p<0.05$; ${ }^{* *} p<0.01$; and ${ }^{* * *} p<0.001$.

\section{RESULTS}

In our search of antiviral drug candidates (Kim et al., 2019), pralatrexate was initially found to be an oseltamivir-comparable candidate drug effective against seasonal influenza viruses (Fig. 1). The $50 \%$ inhibitory concentrations $\left(\mathrm{IC}_{50}\right)$ of pralatrexate against all four tested influenza viruses were much lower than those of oseltamivir, and especially against the $\mathrm{A} / \mathrm{H} 1 \mathrm{~N} 1$ and $\mathrm{A} / \mathrm{H} 3 \mathrm{~N} 2$ subtypes, pralatrexate appeared to exhibit far better efficacy (Table 1). To evaluate its extended efficacy against SARS-CoV-2, we examined pralatrexate using cell-based assays. In Vero cells, pralatrexate appeared to interfere with viral RNA synthesis (Fig. 2). At higher concen-
A Oseltamivir in MDCK cells, $72 \mathrm{hpi}$

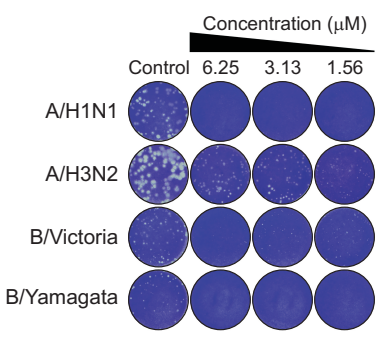

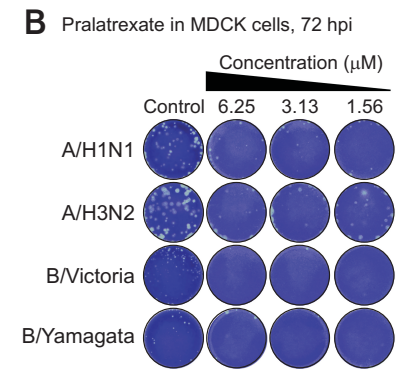

B
Fig. 1. Inhibitory effects of pralatrexate against influenza. (A, B) Pralatrexate was screened for its anti-influenza efficacy by a plaque-reduction assay in MDCK cells. Oseltamivir carboxylate was used as a control. A/H1N1, A/Korea/01/2009; A/H3N2, A/ Perth/16/2009; B/Victoria, B/Brisbane/60/2008; and B/Yamagata, B/Wisconsin/01/2010. trations, pralatrexate showed some cytotoxicity, but it reduced viral RNA copies of SARS-CoV-2 by less than $0.1 \mu \mathrm{M}$ without cytotoxicity at $24 \mathrm{hpi}$. At $48 \mathrm{hpi}$, pralatrexate still exhibited efficacy against SARS-CoV-2, and its $I_{50}$ values were determined to be $0.020-0.028 \mu \mathrm{M}$ (Fig. 2A, Table 2). Pralatrexate also effectively inhibited the replication of SARS-CoV-2 (Fig. 2B). In Vero cells, $0.1 \mu \mathrm{M}$ pralatrexate reduced viral replication with almost two log scales at $24 \mathrm{hpi}$ with statistical significance $\left({ }^{* *} p<0.01\right.$ and $\left.{ }^{* * *} p<0.001\right)$, and at $48 \mathrm{hpi}$, it could still curb viral replication. However, the anti-SARS-COV-2 effects of pralatrexate appeared to be diminished at $72 \mathrm{hpi}$ (Fig. 2B).

We then evaluated the anti-SARS-CoV-2 efficacy of pralatrexate in human lung epithelial Calu- 3 cells by comparing it to that of hydroxychloroquine (Fig. 3). Both drugs exhibited no cytotoxicity in Calu-3 cells. However, only pralatrexate successfully inhibited the RNA synthesis of SARS-CoV-2, whereas hydroxychloroquine showed no efficacy (Fig. 3A and $B)$. Given these results, the $I C_{50}$ values of pralatrexate and hydroxychloroquine were determined to be $0.054 \mu \mathrm{M}$ and $107.8 \mu \mathrm{M}$, respectively, and the selective index $(\mathrm{SI})$ value of pralatrexate was more than 1,800 -fold higher than that of hydroxychloroquine (Table 2). The effects of pralatrexate on the replication of SARS-CoV-2 were also investigated in Calu3 cells. Compared to hydroxychloroquine (Fig. 3D), 1.56-50 $\mu \mathrm{M}$ pralatrexate showed significantly higher inhibitory effects against the replication of SARS-CoV-2 at 48 and $72 \mathrm{hpi}$, with statistical significance $\left({ }^{* * *} p<0.001\right.$ at 48 and 72 hpi) (Fig. 3C). When added to cell supernatants after infection in the timeto-addition assay, pralatrexate exhibited anti-SARS-CoV-2 efficacy in a time-dependent manner. Treatment before $9 \mathrm{hpi}$ could curb viral replication by almost $90 \%$ compared to the

Table 1. $I C_{50}$ values of pralatrexate against seasonal influenza viruses

\begin{tabular}{lcccc}
\hline \multirow{2}{*}{ Chemical } & \multicolumn{1}{c}{$\mathrm{IC}_{50}$ values $(\mu \mathrm{M})$ against seasonal influenza viruses } \\
\cline { 2 - 5 } & $\mathrm{A} / \mathrm{H} 1 \mathrm{~N} 1$ & $\mathrm{~A} / \mathrm{H} 3 \mathrm{~N} 2$ & $\mathrm{~B} /$ Victoria & $\mathrm{B} /$ Yamagata \\
\hline Pralatrexate & 0.068 & 0.379 & 0.009 & 0.042 \\
Oseltamivir & 85.01 & 453.7 & 7.126 & 0.527 \\
\hline
\end{tabular}

${ }^{\mathrm{a} A} \mathrm{~A} / \mathrm{H} 1 \mathrm{N1}, \mathrm{A} /$ Korea/01/2009; A/H3N2, A/Perth/16/2009; B/Victoria, B/Brisbane/60/2008; and B/Yamagata, B/Wisconsin/01/2010.
A

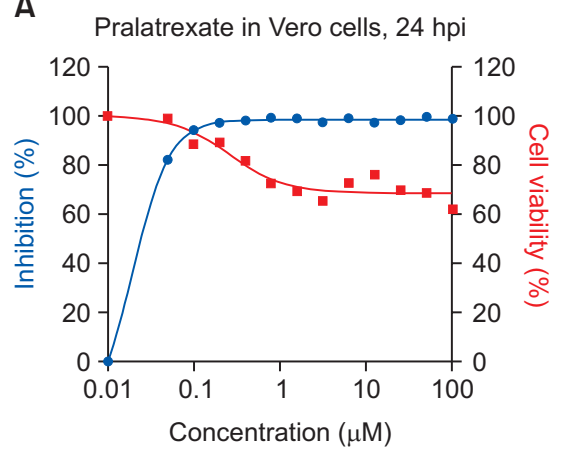

B

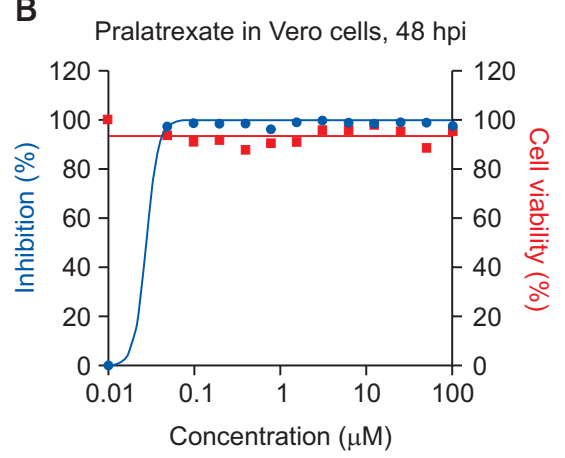

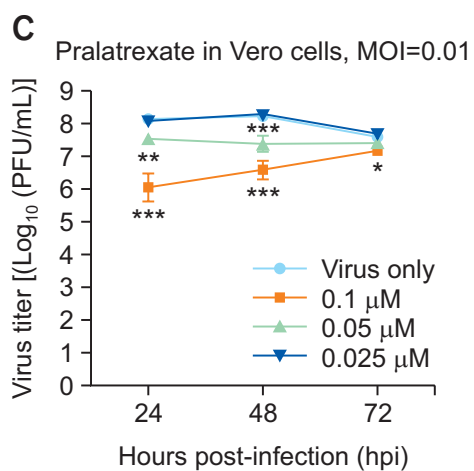

Fig. 2. Inhibitory effects of pralatrexate against SARS-CoV-2 in Vero cells. (A, B) Using qRT-PCR, viral RNAs of SARS-CoV-2 were detected at 24 and $48 \mathrm{hpi}$ with pralatrexate $(0.78$ to $100 \mu \mathrm{M})$ treatment in Vero cells. Cytotoxicity $\left(\mathrm{CC}_{50}, 50 \%\right.$ cytotoxicity concentration) was assessed at the same concentrations of pralatrexate. (C) Antiviral effects of pralatrexate $(0.025,0.05$, or $0.1 \mu \mathrm{M})$ on the replication kinetics of SARS-CoV-2 were evaluated in Vero cells. A virus-only group was treated with cell culture medium. The results were obtained from three independent experiments. The error bar denotes the standard deviation (SD). ${ }^{*} p<0.05 ;{ }^{* *} p<0.01$; and ${ }^{* * *} p<0.001$. 
viral replication titer of a PBS-treated control, and even at 11 or $13 \mathrm{hpi}$, pralatrexate could inhibit the replication of SARSCoV-2 by more than $60 \%$ compared to the control (Fig. 4).

\section{DISCUSSION}

Given the time and costs of new drug discovery, drug repurposing may have great advantages, and it might be the reason that FDA-approved remdesivir and hydroxychloroquine have been investigated to treat COVID-19 patients (FDA, 2020; $\mathrm{WHO}, 2020 \mathrm{~b})$. For a similar reason, we also investigated the in

Table 2. Antiviral and cytotoxic profiles of pralatrexate against SARSCoV-2 in cells

\begin{tabular}{lccccc}
\hline Chemical & Cell & $\begin{array}{c}\text { Time } \\
(\mathrm{hpi})\end{array}$ & $\begin{array}{c}\mathrm{IC}_{50} \\
(\mu \mathrm{M})\end{array}$ & $\begin{array}{c}{ }^{\mathrm{a}} \mathrm{CC}_{50} \\
(\mu \mathrm{M})\end{array}$ & $\begin{array}{c}{ }^{\mathrm{b}} \mathrm{SI} \\
\text { value }\end{array}$ \\
\hline Pralatrexate & Vero & 24 & 0.020 & $>100$ & $>5,000$ \\
& & 48 & 0.028 & $>100$ & $>3,571$ \\
& Calu-3 & 48 & 0.054 & $>100$ & $>1,851$ \\
$\begin{array}{l}\text { Hydroxychlo- } \\
\text { roquine }\end{array}$ & Calu-3 & 48 & 107.8 & $>100$ & 0.93 \\
\hline
\end{tabular}

${ }^{\mathrm{a}} \mathrm{CC}_{50}, 50 \%$ cytotoxic concentration; and ${ }^{\mathrm{b}} \mathrm{SI}$, selective index. vitro anti-SARS-CoV-2 efficacy of pralatrexate using cell-based assays. Initially, we observed that it had antiviral effects against different (sub)types of seasonal influenza viruses (Fig. 1, Table 1). In fact, pralatrexate has been used to treat relapsed or refractory peripheral T-cell lymphoma. It has been reported that pralatrexate may induce the depletion of thymidine monophosphate inside the cell (Hong et al., 2019). Recently, Zhang et al. (2020) suggested the potential binding of pralatrexate to the RdRp catalytic site of SARS-CoV-2, which was investigated using a hybrid screening procedure. At present, we do not know exactly the mode(s) of action (MOA) of pralatrexate against SARS-CoV-2 and influenza viruses. Given these suggested biological mechanisms of pralatrexate, we speculated that pralatrexate might exert its effects by interrupting RNA synthesis of different RNA viruses. Consistently, pralatrexate interfered with SARS-CoV-2 RNA synthesis in Vero cells (Fig. $2 A)$. Despite its cytotoxicity at relatively higher concentrations, pralatrexate impeded viral RNA synthesis as early as $24 \mathrm{hpi}$, and its $I_{50}$ value was determined to be $0.020 \mu \mathrm{M}$ (Table 2). Considering cytotoxicity changes between 24 and 48 hpi (Fig. $2 \mathrm{~A}$ ) and different inhibitory effects on viral replication between 24 and 48 hpi (Fig. 2B), it might be beneficial if pralatrexate is treated more than once at the early phase of SARS-CoV-2 infection. The results of the time-to-addition assay might also support this suggestion (Fig. 4).

Notably, pralatrexate showed different inhibitory effects
A

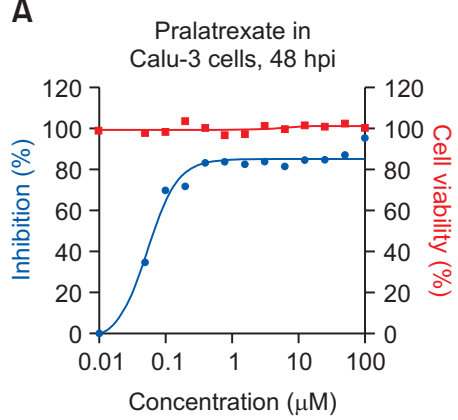

B

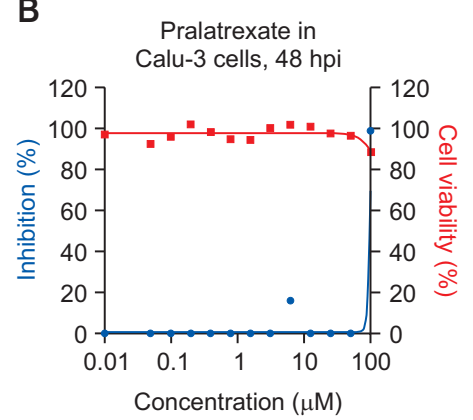

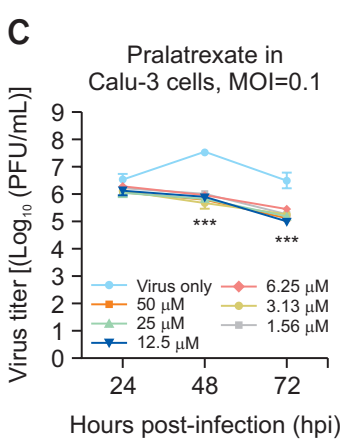

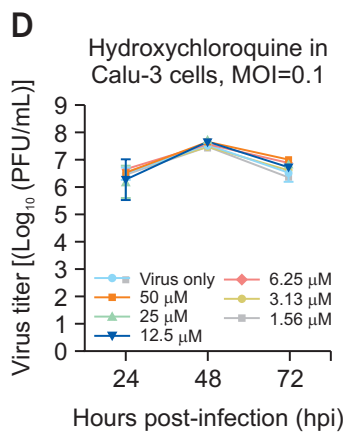

Fig. 3. Inhibitory effects of pralatrexate against SARS-CoV-2 in Calu-3 cells. (A, B) Using qRT-PCR, viral RNAs of SARS-CoV-2 were detected at $48 \mathrm{hpi}$ with pralatrexate or hydroxychloroquine $(0.78-100 \mu \mathrm{M})$ treatment in Calu-3 cells. Cytotoxicity was also assessed for the same concentrations of pralatrexate or hydroxychloroquine. (C, D) Antiviral effects of pralatrexate or hydroxychloroquine $(1.56$ to $50 \mu \mathrm{M})$ on the replication kinetics of SARS-CoV-2 were evaluated in Calu-3 cells. A virus-only group was treated with cell culture medium. The results were obtained from three independent experiments. The error bar denotes the SD. ${ }^{* * *} p<0.001$.
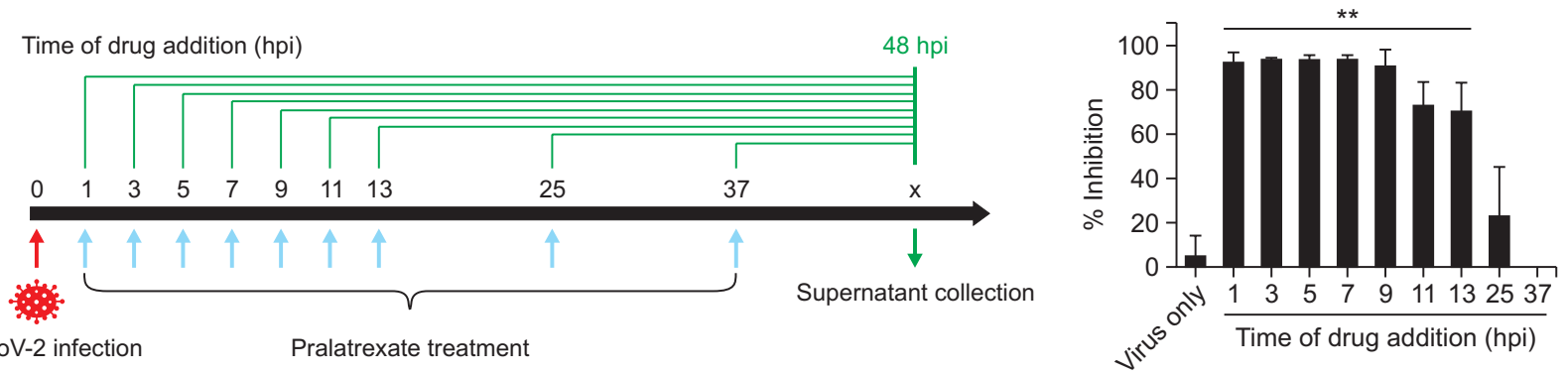

SARS-CoV-2 infection

Pralatrexate treatment

Fig. 4. Time-to-addition effects of pralatrexate against SARS-CoV-2 in Calu- 3 cells. The time-to-addition effects of pralatrexate (12.5 $\mu M)$ on the replication kinetics of SARS-CoV-2 were evaluated in Calu- 3 cells. After infection (MOI=0.1), pralatrexate was added to the cell supernatants at each indicated time point. The cell supernatants were then collected at $48 \mathrm{~h}$ after the addition time and used for titration by the plaque assay in Vero cells. A virus-only group was treated with cell culture medium. The error bar denotes the SD. ${ }^{* *} p<0.01$. 
on the replication kinetics of SARS-CoV-2 in Vero and Calu3 cells (Fig. 2, 3). In Vero cells, pralatrexate more reduced the replication of SARS-CoV-2 at $24 \mathrm{hpi}$ than at $48 \mathrm{hpi}$. In the qRT-PCR assay in Vero cells, pralatrexate also exhibited better effects at $24 \mathrm{hpi}$ than at $48 \mathrm{hpi}$. Given the half-life of pralatrexate (12-18 h) (Drugbank, 2021), these results might be acceptable. However, the antiviral effects of pralatrexate were maximized at $48 \mathrm{hpi}$ in Calu-3 cells, not at as early as $24 \mathrm{hpi}$. This discrepancy suggests that the onset of pharmacological action of pralatrexate might be cell- or host-dependent, which should be considered in determining a medication administration protocol. Furthermore, as indicated in the cytotoxicity assay, the potential adverse effects of pralatrexate on normal cells and its exact MOA against SARS-CoV-2 must also be explored further in suitable animal models.

With therapeutic benefits and limits, the FDA-approved anticancer drug pralatrexate can be repurposed upon approval of its pharmacological effects to equip ourselves against COVID-19 in the influenza virus-circulating winter season, and it may also reduce health risks in cancer patients, providing dual beneficial effects.

\section{ACKNOWLEDGMENTS}

This study is supported by a grant from the National Research Foundation of Korea (NRF) funded by the Ministry of Science and ICT, Republic of Korea (Grant No. NRF-2018 M3A9H4056537).

\section{REFERENCES}

Beigel, J. H., Tomashek, K. M., Dodd, L. E., Mehta, A. K., Zingman, B. S., Kalil, A. C., Hohmann, E., Chu, H. Y., Luetkemeyer, A., Kline, S., Lopez de Castilla, D., Finberg, R. W., Dierberg, K., Tapson, V., Hsieh, L., Patterson, T. F., Paredes, R., Sweeney, D. A., Short, W. R., Touloumi, G., Lye, D. C., Ohmagari, N., Oh, M. D., RuizPalacios, G. M., Benfield, T., Fatkenheuer, G., Kortepeter, M. G., Atmar, R. L., Creech, C. B., Lundgren, J., Babiker, A. G., Pett, S., Neaton, J. D., Burgess, T. H., Bonnett, T., Green, M., Makowski, M., Osinusi, A., Nayak, S. and Lane, H. C.; ACTT-1 Study Group Members (2020) Remdesivir for the treatment of Covid-19 - final report. N. Engl. J. Med. 383, 1813-1826.

CDC (2021a) COVID Data Tracker. COVID-19 Vaccinations in the United States. Centers for Disease Control and Prevention. Available from: https://covid.cdc.gov/covid-data-tracker/\#vaccinations/ [accessed 2021 Jan 31].

CDC (2021b) COVID Data Tracker. United States COVID-19 Cases and Deaths by State. Centers for Disease Control and Prevention. Available from: https://covid.cdc.gov/covid-data-tracker/\#cases_ casesinlast7days/ [accessed 2021 Jan 31].

CDC (2021c) Different COVID-19 Vaccines. Centers for Disease Control and Prevention. Available from: https://www.cdc.gov/ coronavirus/2019-ncov/vaccines/different-vaccines.html/ [accessed 2021 Jan 15].

Corman, V. M., Landt, O., Kaiser, M., Molenkamp, R., Meijer, A., Chu, D. K., Bleicker, T., Brunink, S., Schneider, J., Schmidt, M. L., Mulders, D. G., Haagmans, B. L., van der Veer, B., van den Brink, S., Wijsman, L., Goderski, G., Romette, J. L., Ellis, J., Zambon, M., Peiris, M., Goossens, H., Reusken, C., Koopmans, M. P. and Drosten, C. (2020) Detection of 2019 novel coronavirus (2019-nCoV) by real-time RT-PCR. Euro Surveill. 25, 2000045.

Drugbank (2021) Pralatrexate. Accession number: DB06813. Available from: https://go.drugbank.com/drugs/DB06813/ [created 2010 Sep 14; updated 2021 Feb 04].
ECDC (2021) COVID-19 Situation Update for the EU/EEA, as of Week 3. European Centre for Disease Prevention and Control. Available from: https://www.ecdc.europa.eu/en/cases-2019-ncov-eueea/ [updated 2021 Jan 28].

FDA (2020) COVID-19 Treatment Guidelines. Antiviral Drugs That Are Approved or Under Evaluation for the Treatment of COVID-19. U.S. Food and Drug Administration. Available from: https://www. covid19treatmentguidelines.nih.gov/antiviral-therapy/ [last updated 2020 Nov 3].

Hong, J. Y., Yoon, D. H., Yoon, S. E., Kim, S. J., Lee, H. S., Eom, H. S., Lee, H. W., Shin, D. Y., Koh, Y., Yoon, S. S., Jo, J. C., Kim, J. S., Kim, S. J., Cho, S. H., Lee, W. S., Won, J. H., Kim, W. S. and Suh, C. (2019) Pralatrexate in patients with recurrent or refractory peripheral T-cell lymphomas: a multicenter retrospective analysis. Sci. Rep. 9, 20302.

Jones, L., Palumbo, D. and Brown, D. (2021) Coronavirus: How the Pandemic Has Changed the World Economy. BBC News. Available from: https://www.bbc.com/news/business-51706225/ [2021 Jan 24].

Kim, J. I., Lee, S., Lee, G. Y., Park, S., Bae, J. Y., Heo, J., Kim, H. Y., Woo, S. H., Lee, H. U., Ahn, C. A., Bang, H. J., Ju, H. S., Ok, K., Byun, Y., Cho, D. J., Shin, J. S., Kim, D. Y., Park, M. S. and Park, M. S. (2019) Novel small molecule targeting the hemagglutinin stalk of influenza viruses. J. Virol. 93, e00878-19.

The Lancet (2020) COVID-19: the worst may be yet to come. Lancet 396, 71.

Van Lancker, W. and Parolin, Z. (2020) COVID-19, school closures, and child poverty: a social crisis in the making. Lancet Public Health 5, e243-e244.

WHO (2020a) WHO Coronavirus Disease (COVID-19) Dashboard. World Health Organization. Available from: https://covid19.who.int/ [accessed 2021 Jan 31].

WHO (2020b) COVID-19 Studies from the WHO Database. World Health Organization's International Clinical Trials Registry Platform (WHO ICTRP). Available from: https://clinicaltrials.gov/ct2/who_table/ [accessed 2020 May 19].

WHO (2021a) "Solidarity" Clinical Trial for COVID-19 Treatments. Latest Update on Treatment Arms. World Health Organization. Available from: https://www.who.int/emergencies/diseases/novel-coronavirus-2019/global-research-on-novel-coronavirus-2019-ncov/ solidarity-clinical-trial-for-covid-19-treatments/.

WHO (2021b) Draft Landscape and Tracker of COVID-19 Candidate Vaccines. World Health Organization. Available from: https://www. who.int/publications/m/item/draft-landscape-of-covid-19-candidate-vaccines/ [accessed 2021 Jan 26].

WHO Solidarity Trial Consortium, Pan, H., Peto, R., Henao-Restrepo, A. M., Preziosi, M. P., Sathiyamoorthy, V., Abdool Karim, Q., Alejandria, M. M., Hernandez Garcia, C., Kieny, M. P., Malekzadeh, R., Murthy, S., Reddy, K. S., Roses Periago, M., Abi Hanna, P., Ader, F., Al-Bader, A. M., Alhasawi, A., Allum, E., Alotaibi, A., AlvarezMoreno, C. A., Appadoo, S., Asiri, A., Aukrust, P., Barratt-Due, A., Bellani, S., Branca, M., Cappel-Porter, H. B. C., Cerrato, N., Chow, T. S., Como, N., Eustace, J., Garcia, P. J., Godbole, S., Gotuzzo, E., Griskevicius, L., Hamra, R., Hassan, M., Hassany, M., Hutton, D., Irmansyah, I., Jancoriene, L., Kirwan, J., Kumar, S., Lennon, P., Lopardo, G., Lydon, P., Magrini, N., Maguire, T., Manevska, S., Manuel, O., McGinty, S., Medina, M. T., Mesa Rubio, M. L., Miranda-Montoya, M. C., Nel, J., Nunes, E. P., Perola, M., Portoles, A., Rasmin, M. R., Raza, A., Rees, H., Reges, P. P. S., Rogers, C. A., Salami, K., Salvadori, M. I., Sinani, N., Sterne, J. A. C., Stevanovikj, M., Tacconelli, E., Tikkinen, K. A. O., Trelle, S., Zaid, H., Rottingen, J. A. and Swaminathan, S. (2020) Repurposed antiviral drugs for Covid-19 - interim WHO Solidarity trial results. N. Engl. J. Med. 384, 497-511.

Zhang, H., Yang, Y., Li, J., Wang, M., Saravanan, K. M., Wei, J., TzeYang Ng, J., Tofazzal Hossain, M., Liu, M., Zhang, H., Ren, X., Pan, Y., Peng, Y., Shi, Y., Wan, X., Liu, Y. and Wei, Y. (2020) A novel virtual screening procedure identifies Pralatrexate as inhibitor of SARS-CoV-2 RdRp and it reduces viral replication in vitro. PLoS Comput. Biol. 16, e1008489. 